\title{
Production of T. aestivum L. hybrids with Ae. neglecta under conditions of Azerbaijan
}

\author{
Namazova L.H.*, Aliyeva A.J. \\ Genetic Resources Institute, ANAS, Baku, Azerbaijan \\ *e-mail:leman.namazova.92@mail.ru
}

Ae. neglecta [syn. triaristata Willd.; $(2 n=4 x=28$, genome $U U M M)$ ] is an important gene source for favourite alleles and genes introducing via intergeneric hybridization in wheat improvement. The common wheat line 171ACS \{Aegilotriticale [(T. durum Desf. $\times$ $\times$ Ae. tauschii Coss.) $\times$ Secale cereale L. ssp. segetale Zhuk.] $\times$ T. aestivum L. 'Chinese Spring' $\}$ crossed resiprocally with 3 genotypes of Ae. neglecta originated and collected from different populations of Azerbaijan. 1 genotype of Aegilops collected from Siyazan (\#1), 2 [black (\#2) and white (\#3) accessions] collected from Girdimanchay. Field works were carried out at the Absheron Research Station of Genetic Resources Institute of ANAS. No embryo rescue or hormone treatment was applied for the production of $\mathrm{F}_{0}$ seeds. Seed setting and germination ability were different depend on the genotypes. The highest seed setting observed in combination 171ACS $\times \# 3(51.72 \%)$. The second place taked by common wheat hybrid with \#2 (23.58\%). It is followed by $171 \mathrm{ACS} \times \# 1$ that demonstrated $20.00 \%$ seed-production rate. The lowest seed setting observed reciprocal hybrids of last combination (15.62\%). They gave 27, 19, 7 and 1 seedlings, respectively, that were transplanted into the experimental field for further investigations. Morphologically, $\mathrm{F}_{1}$ hybrids between bread wheat and \#1 resembled goatgrass, but others remain common wheat plant. However, phenotype of their resiprocal hybrids doesn't differ from each other. Pollen mother cells (PMCs) for studies of meiotic chromosome behavior were prepared by means of the standard Carnoy fixative and acetocarmine squash method and observed 35 chromosomes in $\mathrm{F}_{1}$ plants, as expected. Significant differences in chromosome conjugation of reciprocal hybrids had not been observed, thus, they had approximatedly same amount of bi- and univalents. 